Sen and Williams. Utilitarianism and beyond. Cambridge University Press, 1982. Williams B. Morality: An Introduction to Ethics. London, England; Cambridge University Press; 1972

17. Bentham J. The principles of morals and legislation. 1989 ; chap1-5.

18. Patrick, Bush, Chen. Methods for measuring levels of well-being for a health status index. Health Service Research. 1973;8:228-245.

19. Nord $\mathrm{E}$. The relevance of health state after treatment in prioritising between different patients. $J$ Med Ethics. 1993;1:37-42.

20. Drummond gives references to numerous other indexes: Sackett DL, Torrance GW. The utility of different health states as perceived by the general public. JChron Dis. 1978;31:697-704. Boyle MH, Torrance GW, Sinclair JC, Horwood. Economic evaluation of neonatal intensive care of very low birth-weight intants. N Eng J Med. 1983;308:1330-37. Drummond MF, Stodart GL, Torrance GW. Methods for the Economic Evaluation of Health Care Programmes. Oxford, Eng; Oxford University Press; 1986.

21. Rawls $\mathrm{J}$. Theory of Justice. Cambridge, Mass; Harvard University Press; 1971.

22. Harris, John. Unprincipled QALYs. JMed Ethics. 1991;4:185-188.

23. Brock D. The value of prolonging human life. Philosophical Studies. 1986,50:421

\title{
Some Ethical Principles for Adult Critical Care
}

\author{
Kenneth Kipnis PhD, Anita Gerhard MD
}

State of the art in approaching several of the most disturbing problems involving end-of-life decision-making in an intensive care setting is applicable to other contexts as well. Developed as part of the curriculum at the John A. Burns School of Medicine at the University of Hawaii, the material is intended as a reflection of current work in health care ethics, strongly supported by literature, and generally consistent with current legal trends. But it also has developed into something of a consensus document, having been widely circulated in various versions, repeatedly presented to professional audiences dozens of times in Hawaii, and improved by countless comments and suggestions. The focus here is on the standards for withholding and withdrawing treatment. It should be noted that some important types of ethical problems are not covered: In particular, scarce resource problems (including some related questions involving medical futility), maternal-fetal and pediatric issues, and questions involving the notification of potentially affected third parties.

\section{Decisionally Capacitated Patients}

For decisionally capacitated patients, it can be axiomatic that health care professionals must secure informed consent prior to treatment. There is almost no debate about this issue. The little discussion is occurring only at the distant margins-refusals by pregnant women and patients with MDR TB. And even in these cases it cannot be said there is a consensus that contradicts the axiom. In essence, where informed consent has been with held or withdrawn, health care professionals, lacking needed permission, are not at liberty to treat. Refusals of treatment by

Kenneth Kipnis PhD

Department of Philosophy

University of Hawaii at Manoa

Anita Gerhard MD

Department of Psychiatry

John A. Burns School of Medicine

University of Hawail at Manoa decisionally capacitated, informed adults are decisive: Relatives and health care professionals have no ethical or legal authority to overturn their medical decisions.

\section{Competency and Decisional Capacity}

All adults are presumed to be competent and decisionally capacitated. This assumption is rebuttable. In this context, the term "incompetency" must be distinguished from "decisional incapacitation," by far the more useful of the two concepts. The former is a legal status that is imposed by courts. A judge, generally following the testimony of a psychiatrist, can find an adult to be legally incompetent and will therefore appoint a guardian who is empowered to make decisions on behalf of the adult, now a ward. Judicial declarations of incompetency are rarely required in the ICU. On the other hand, capacity and incapacity are action-specific concepts that are often clinically applicable. As regards some health-care decision, a patient is sufficiently capacitated to make that particular decision if, at a minimum, he or she has the capacities 1) to understand the problem, 2) to understand the risks and benefits of the available alternatives (including no treatment), and 3) to express a choice. It is possible for a legally incompetent patient-for example, a mature minor - to be decisionally capacitated. Likewise, a competent patient may be decisionally incapacitated, as when a patient is in denial about the medical problem.

\section{Informed Consent}

Consistent with this analysis of decisional capacity as a minimum standard, a patient is sufficiently informed to give informed consent if he or she:

1. Understands the medical problem,

2. understands what the health care professional proposes to do,

3. understands the available alternatives, including no treatment, and 
4. understands the risks and benefits attaching to each of these alternatives.

What counts as a risk and what counts as a benefit is based on the patient's values. A facial scar can have one assessment to a fashion model and quite another to a Prussian military officer.

Ethically and legally, informed consent is at the heart of the relationship between health care professionals and patients. The question is not whether the heath care professional has accurately set out the facts but, rather, whether the patient has understood. Informed consent is a process of patient education and assessment of the patient's knowledge. The underlying condition is explained the options, and the risks and benefits attaching to each option (including the option of no treatment). Time is allowed for questions and the patient's comprehension is tested, going back over what has not been understood, and then reassessing comprehension. Contrary to the opinion of many, the signature on the form is not the informed consent but merely rebuttable evidence that this process has been successfully carried out. In giving informed consent, a patient assumes a measure of responsibility for the decision to implement the medical procedure and gives health care professionals permission to carry it out.

\section{The Patient's Values}

Decisional capacity is often said by commentators to require, in addition to 1 to 4 above:

5 . some relatively stable set of personal values and

6. the capacity to employ reason in applying these values to situations.

This higher standard is met when the patient can, so to speak, "tell a story" in which the decision, under the circumstances, makes sense against the background of his or her personal values. In assessing decisional capacity it may sometimes be appropriate to explore the patient's values and how these have been applied to the medical alternatives. Where, for example, a patient is rejecting a relatively non-burdensome intervention that promises significant subjective advantages, it is permissible to seek to understand the patient's values, stability, and how these are being applied. A simple and effective way of determining whether conditions 5 and 6 are met is to ask: "Please help me understand why you are making this decision."

In seeking to understand how the patient's decision is supported by the reasoned application of relatively stable values, it is important that health care professionals be able to honor the patient's values, even if these are very different from their own. Caution should be exercised to ensure that the standard of rationality that is applied to the patient is not outcome-based; ie, not set so high that only agreement with the physician's recommendation could count as adequate evidence of decisional capacity.

\section{Determinations of Capacity}

Ideally, determinations of decisional capacity (minimum standard) should be made and charted before the patient is asked to express a choice. If, however, there are questions about the reasoned nature of the choice-as when the patient is refusing low-burden, high-benefit treatment-it is recommended to ask the patient to explain why he or she has chosen that alternative: "Please help me understand why you want to do this." But the willingness to respond to such questioning is not a prerequisite for honoring consent in an adult patient. (The ability to respond coherently to such questions, however, might be relevant in rebutting a minor's presumed incapacitation.) Referrals to the hospital ethics committee and/or an ethics consultation (where available) are advised in enigmatic refusal cases, where patients are unwilling to reveal their reasons for refusing treatment.

Psychiatric consults are appropriate to determine whether a psychological state, such as the adoption of unusual beliefs or a shift in personal values, is traceable to mental illness. But note that mental illness calls decisional capacity into question only when it directly affects the patient's decision. A diagnosis of mental illness is not the same as a determination of decisional incapacity, for mental illness can preserve capacity in some areas while compromising it in others. Accordingly patients with psychiatric symptoms and/or diagnoses may well be decisionally capacitated. However conditions such as dementia, delirium, depression, mania, and delusions specific to treatment may well call decisional capacitation into question.

\section{Decisionally Incapacitated Patients}

Decisionally capacitated patients have the ethical standing to make medical treatment choices on their own. The discussion above sets out what are essentially standard criteria for distinguishing between patients who are decisionally capacitated in this sense and those who aren't. Where patients are found to be decisionally incapacitated, the literature is again fairly consistent in recommending a three-step process. First, determine if there is an advance directive. Second, if unable to obtain an advance directive, endeavor to apply the "substituted judgment test" (See below). And third, in the event that the substituted judgment test cannot be applied, apply the "best interests" test. In all of these cases, the ideal is to approximate, as well as possible, the patient's own autonomous decision.

\section{Advance Directives}

Where an adult patient has lost decisional capacity, medical decisions should be made, ideally, in accordance with some previously executed advance directive: A living will or a durable power of attorney. Advance directives are indicated where:

a) incapacitation is anticipated (eg, Alzheimer's disease) and/or

b) conflicts are anticipated with or within the patient's family.

Neither relatives nor health care professionals have the legal or ethical power to countermand the provisions in an advance directive.

Advance directives are fundamentally of two types. There is the "living will" containing instructions for medical treatment in the event the patient becomes incapacitated. The document specifies some set of medically determinable conditions (Two common ones are "in the event that I am terminally ill" and "in the event that I have lost the capacity to participate in medical treatment decisions with no reasonable expectation of regaining that capacity") and a set of instructions to follow when it is determined that the listed condition or conditions obtain. And there is the "durable power of attorney" which delegates the authority to make medical treatment decisions to some third party who is required to act in accordance with the patient's values. (See the discussion below on the "substituted judgment test." Sometimes the two documents are combined, including instructions, as living wills do, but also designating a proxy decision-maker in the event it become unclear how the instruc- 
tions are to be interpreted.

Where a physician has personal reservations about carrying out its provisions, the care of the patient should be transferred in a timely way to a physician who can give effect to the patient's decision. Health care professionals should be aware that the provisions of advance directives may vary. These should be studied with care.

\section{The "Substituted Judgment" Test}

Where a patient who has lost decisional capacity lacks an advance directive, medical decisions should be made in accordance with the "substituted judgment" test. It is critical, in discussions with the patient's friends and family, to frame the question properly. Those who have been close to the patient should be asked for information about the patient's hopes, beliefs, values, goals, concerns, etc, with the intention of identifying the course of action that the patient would have chosen under the existing circumstances.

It is a good idea to begin a family conference by specifying that the concern is to try to reach agreement about the best decision rather than determine who has the right to decide. If everyone can agree about what is the right thing to do, there is no need to reach the question of who is the one to decide. Note that relatives should not be asked for their decision nor should they be asked about their own preferences. They should instead be asked for specific information that can assist in reaching a shared understanding of how the patient would have made the decision.

The conversation should focus exclusively on what those assembled know about the patient: The stories, the quotes, the insights into the patient's deepest commitments. "Did he or she ever say anything about how these decisions should be made or about how these problems should be approached?" Only after these issues have been amply explored-with everyone having had a chance to contribute and hear what others have to say-it should be asked, "How can we best respect what this person stood for?" Using this approach, medical decisions should reflect the patient's values, as these are discerned by those who have been closest to the patient, those best situated to be able to report reliably on what those values were. On some occasions, but only when this approach has failed, relatives and friends may be polled on the question of which person is the one the patient would have been most likely to entrust with such a decision.

Conversations very like this are also appropriate where there is a proxy decision-maker who has been designated by a durable power of attorney. Though, in these cases, the designated proxy does have a right to decide, he or she is still required to make that decision in the light of the patient's expressed values. Hence the exchange of information can be essential in confirming what those values were.

\section{The Best Interests Test}

When a decisionally incapacitated patient has no advance directive and where information is not available about how the patient would have decided - either the patient has never been capacitated or is a "John Doe"-medical decisions should be made using the "best interests" test. For never-capacitated patients, it often makes sense to ask, "What do we know of this patient's sensitivities?" (Warmth, comfort, freedom from pain, etc.) For formerly capacitated patients it can be helpful to ask, "What would the reasonable person in the patient's position choose?" These cases should be referred to the hospital ethics committee.

\section{Contraindicated Treatment}

\section{Above All, Do No Harm}

The ethical principle, Above all, do no harm, prohibits the imposition of burdensome medical treatment that is not expected to provide the patient with any subjective benefit. This principle is most likely to be violated when relatives and other decision-makers are given too free a hand in medical decision-making. Guilt and denial may compel relatives to press for aggressive treatment that the patient is known not to have wanted. Attention to the standards set out in the substitued judgment test can prevent this from occurring.

\section{Medical Futility}

There is no ethical obligation to commence or to continue futile treatment modalities, procedures that are not expected to provide the patient with any subjective benefit. Questions of medical futility can arise when patients and families are in agreement that "everything" should be done. In these cases it is critical that patients and families are clear about what outcomes can and cannot be expected as a consequence of aggressive treatment. The focus should be shifted away from the treatment modalities that are available to the outcomes that can be reasonably expected to flow from those treatments. (See Competency and Decisional Capacity: Minimum standard for informed consent.)

Most cultures have venerable rituals associated with death: Ceremonies that acknowledge the importance of the person who is dying and that solemnize the seriousness of the occasion. It is unfortunate that health care settings are often prepared to respond to familial apprehension only by imposing medical treatment: A kind of high-tech shamanism. What may be more appropriate to families is intensive spiritual care; a mobilization of social support systems that can assist the family through its loss and transition.

Psychiatric consults may be indicated if, for example, denial or some other delusion specific to a treatment decision is playing a role in the demand for futile treatment. Consultation with an institutional Ethics Committee may also be appropriate in cases where patients and families persist in demanding treatments that do not promise benefits that are subjectively valued by the patient.

\section{Withdrawal and Withholding of Life Support}

Where a treatment modality is not owed to the patient (where consent has been withdrawn or where the procedure is not expected, on balance, to provide a benefit to the patient) this treatment modality may be withdrawn or withheld. The same conditions that justify withholding treatment also justify withdrawing it. There is no presumption that, once begun, no matter how futile, life-sustaining medical procedures must be continued. The maintenance of organic life is not, in and of itself, a benefit to the patient. "Benefit" here is to be understood as relative to the patient's values, as discussed in Decisionally Capacitated Patients. Note that the decision to withdraw or withhold life support is not a decision to abandon the patient. Other treatment modalities, especially pain control and comfort care ("aggressive palliative care"), may be required.

\section{Brain Death}

Therapeutic treatment modalities are decisively contraindicated for all patients who are dead, including patients who are "brain dead." It is generally unwise to use the expression "brain dead" 
with patients' families as the state that is referred to is not one of qualified death. The patient should be described as having died, adding that some of the bodily organs are being supported mechanically in case they may be used for transplants. It is not appropriate to ask relatives for permission to disconnect support equipment in these cases. After death has occurred, that which used to be the body of the patient can be kept on organ supportnot life support-until organs usable for transplant purposes are harvested or until it is established that consent to harvest the organs is not available.

\title{
The Decision to Withdraw Tube Feeding
}

\author{
Joy F. Murakami MD, Warren F. Wong MD
}

Physicians involved in the care of elderly patients are often faced with end-of-life decisions including withholding or withdrawal of tube feeding. More than $80 \%$ of deaths take place in the hospital or nursing home and the prolongation of life by medical technology has replaced natural processes. 'We believe the availability of life-sustaining medical technology including tube feeding does not make physicians ethically obligated to use it once it is known that health and function cannot be restored and the burdens outweigh the benefits. Patients and their surrogate decision-makers have a right to refuse life-sustaining medical treatment they find burdensome. Tube feeding as a medical treatment, withholding of tube feeding as equivalent to withdrawal of tube feeding, the benefits versus the burdens of tube feeding, and the decision-making process involved in the withdrawal of medical treatment are considered Hawaii's statutes as they apply to decision-making and examples of cases to illustrate how these concepts are pertinent to patients whom we encounter in clinical practice are discussed.

\section{Tube Feeding as a Medical Treatment}

Some individuals view enteral feeding as basic supportive care that is ethically obligatory, and therefore, should not be withheld or withdrawn. The provision of food and water is believed to be symbolic of caring, comfort, and compassion. ${ }^{3}$

However, the majority ethical and legal position at this time is to regard enteral and parental nutrition and hydration as life-sustaining medical treatment with proportionate benefits and burdens that must be assessed individually from the perspective of the patient. As with all other forms of medical treatment, tube feeding can be refused or might not be appropriate. It is the obligation of the physician to obtain informed consent prior to the initiation of tube feeding. Over the last decade there have been numerous court cases supporting the right of the competent individual to refuse life-sustaining tube feeding and have expanded this legal concept to include incompetent individuals and individuals not imminently dying (patients who are in persistent vegetative states or who are very debilitated). ${ }^{1-3}$ In 1990 , Justice Sandra Day O'Connor, writing in a concurring opinion for the United States Supreme Court in the Cruzan case, stated unequivocally that artificial feeding should be considered a form of medical intervention. ${ }^{4}$ Despite emerging legal consensus, in several states feeding tubes are explicitly excluded from the types of life-prolonging treatment that may be rejected in an advance directive such as a living will. Since July of 1991, Hawaii's statute has explicitly addressed whether the declarant wants or does not want tube feeding. Patients should, therefore, have an updated declaration.

Tube feeding is a medical treatment, but we contend that all health care treatments, whether regarded as basic supportive care or medical intervention, are subject to a benefit/burden analysis and can be accepted or rejected by an adequately informed patient or surrogate decision-maker.

\section{Withholding Versus Withdrawal of Tube Feeding}

Decisions concerning initiation, withholding and withdrawal of life-sustaining enteral nutrition are very difficult to make. There is not always a clear sense of whether to start tube feedings. When the prognosis is not clear and there is evidence to suggest that nutritional support can help a person regain health and function or allow time to recover, the more prudent decision is to initiate a time-limited trial of tube feeding. Tube feeding can be withdrawn when it becomes clear that therapy is not effective, or that the burdens of prolonging life with tube feeding outweigh the benefits, ${ }^{5}$ or when the patient's prognosis or wishes have been clarified.

Ethicists and the courts equate the act of withdrawing a treatment with the act of withholding a treatment once the appropriate individuals have reached a decision. If withdrawing a treatment is considered more problematic than withholding one, physicians will withhold treatments when they are uncertain as to their benefit, rather than risk not being able to withdraw the treatment later. ${ }^{4}$ This denies many patients potentially beneficial treatments.

Many health care providers believe it is psychologically and emotionally more difficult to withdraw treatment rather than 